\title{
Exploring the Significance of Earning a Social License to Operate in an Urban Setting
}

\author{
Lysa Morishita* and Dirk van Zyl \\ Norman B. Keevil Institute of Mining Engineering, University of British Columbia, 6350 Stores Rd., V6T 1Z4 Vancouver, \\ BC, Canada
}

\begin{abstract}
Mining companies are increasingly approaching the social aspect of sustainable development within the rural communities that neighbour their projects and operations. Rural community engagement requires significant effort and resources, and it can be extremely challenging for mining companies to earn and sustain social capital. The focus on rural, proximal community engagement is not to be understated and has led to significant benefits in many communities. However, opposition to mining projects is often exhibited in urban environments, where there may be potential for mining companies to gain social capital with relative ease. Cities tend to have existing frameworks for community engagement and public activation, such as annual parades and festivals, that make it easy for a mining company to provide financial support or value-in-kind. Local organizations and community groups can achieve the same amount of engagement in an urban environment with significantly less effort required from the mining company. By applying simple marketing principles to community engagement strategies, corporations can increase awareness for their business and encourage city residents to think critically about the origin of resources. Unlike many corporations, mining companies are not marketing or selling products to individual consumers. From this arises the opportunity for a company to use marketing to promote other positive initiatives and, as such, connect their brand with positive messaging thus earning social capital. This may lead to a wide variety of secondary impacts including benefits to recruitment efforts, increased political support, and positive media coverage. This paper explores these matters with special reference to Vancouver, BC, Canada and the mining companies Teck and Goldcorp.
\end{abstract}

Keywords: mining; sustainable development; social capital; social license to operate; urban awareness; public realm

\section{Introduction / Background}

The objectives of this review are to investigate the concept of a social license to operate in an urban environment, with focus on Vancouver, British Columbia, Canada. Basic marketing concepts will be applied in coordination with another approach to social license to operate (SLO). Basic marketing theories rely on a clearly identified baseline and target future. This investigation will outline a scale of social capital (the value of the relationship network and psychological connectedness that exists among people living in a society) that may be applied to a marketing method to measure social license to operate.

Recommendations will be made on how a mining company can earn a social license to operate in Vancouver, and the investigation will probe into why that recommendation is hypothesized to be successful. The language "social license to operate" in this context refers not to any particular mine or project, rather the urban community's acceptance of the company such that it can continue doing business in an urban realm.

The scope of this review is limited to publicly available data only; no interviews or surveys were conducted. This review aims to explore a new concept and further investigation is required prior to application.

\section{Methodology}

This investigation will begin by reviewing the "Traditional" approach to community engagement. This is referring to the methods of community engagement that are perceived to be so well-understood that companies have large platforms and comprehensive strategies to engage with communities associated with their major projects and often claim varying degrees of success.

The focus will then shift to the urban realm. How do other industries interface with the urban realm, and how does that compare to mining companies? Two scenarios will be compared in the realm of Vancouver, British Columbia, Canada: Teck Resources Limited (Teck), and Goldcorp Incorporated (GoldCorp).

The authors will propose the concept of social license to operate in an urban environment. The current state of social capital will be estimated, and a target goal will be defined. Challenges of applying traditional approaches to an urban population will be identified.

\footnotetext{
* Corresponding Author: L. Morishita, lysa.morishita@alumni.ubc.ca, phone: +1 604-5615671 


\section{Analysis}

\section{1 "Traditional" community engagement}

"Traditional" community engagement as used here refers to what companies are doing now. By navigating the websites of some of the world's largest mining companies it is clear that communicating their efforts towards community engagement is a high priority. Based on the metrics that are being reported publicly, trends in traditional community engagement appear to be focused in the following groups:

- Engaging with and hiring Indigenous people;

- Providing healthcare in communities where it is not always available;

- $\quad$ Supporting education and training, before and after entering the workforce; and

- $\quad$ Supporting local business.

These efforts are not to be understated, and must continue to be the focus of corporate engagement efforts. However, this strategy cannot be applied to an urban environment to build social capital.

The following sections will apply theories and approaches introduced by Thomson and Boutilier (2011) as well as basic marketing principles to the role of mining companies in an urban realm.

\subsection{Urban community engagement}

Building social capital in an urban environment has different challenges than in a rural environment. In the context of this review, the target community is a group of people who rarely, if ever, think about the mining industry at all. If the goal is to earn a social license to operate, the objective is to get people to think critically about the mining industry and the role it plays in society. To do that, players in the industry can associate themselves with enduring activities in the urban realm.

Strict distinction must be acknowledged between monetary or in-kind contributions and personal engagement. In rural environments, it has been seen that simply providing money is not an enduring solution. For example, building a hospital to serve a community without healthcare will not solve any problems if there are no doctors or nurses or staff to operate it. However, in urban environments, a cash or inkind contribution may be of equal or greater value to the community and to the mining company.

It is important to note that, in this context, the urban SLO is not in relation to any particular mine or project a mining company may be operating. The urban SLO refers to the entire organization and the publics' acceptance of the company's continued operation.

Corporate sponsorship

The Value of Sponsorship

Sponsorship is an enormous industry in itself that spent over \$57-billion worldwide in 2015 (McClellan 2016). PepsiCo and Anheuser-Busch each spent over \$300-million in 2014 (IEG 2015). What are these companies getting in return for their investment? A study conducted by ANA (2013) reported that 25 percent of marketers "do not gather, analyze, and use data" to make sponsorship decisions, and 58 percent of marketers were at least somewhat dissatisfied with their ability to measure their return on investment from sponsorship.

Corporate sponsorship as a marketing tool has increased tremendously over the last 20 years (Jagre et al 2001). In 2014, spending by North American companies on sponsorships was over \$20-billion and is consistently growing each year (IEG Sponsorship Report 2015). This growth trend can be attributed to the shift of prioritization from just building brands to "activating" brands (Rosen and Minsky 2011). This concept of marketing for engagement can be applied to the mining industry.

\subsection{Teck - Emergency centre}

Teck is a major sponsor of the Teck Emergency Centre at Saint Paul's Hospital. By associating the Teck Resources brand with quality healthcare services, Teck is demonstrating its commitment to health and safety away from the work site, which complements their commitment to health and safety on the worksite.

The contribution by Teck is direct. The renovation and upgrade to the St. Paul's Hospital Emergency Centre allows for high quality, timely emergency health care services to be provided to the public. This outreach not only impacts the patients themselves, but also their loved ones. Does the Teck name on the building change peoples' views on the company and their operations? Will it engage people enough to think "What is 'Teck' and what do they do?"

This is a poignant example of the difference between urban and rural community engagement. Teck's contribution to St. Paul's Hospital was \$2.5-million to the St. Paul's Foundation. An organization like the St. Paul's Foundation does not typically exist in a rural environment. In Vancouver, a strictly monetary donation to healthcare effectively serves the community - this concept is not comparable in a rural environment.

\subsection{GoldCorp - Bard on the beach}

GoldCorp donated \$500,000 to Bard on the Beach, an annual professional Shakespeare festival that presents plays, dramas, and other special events all summer long. The contribution by Goldcorp, while still strictly monetary, is indirect and perhaps more complex. Bard on the Beach creates a community where people can gather, learn, be entertained, and communicate with each other. The impacts of placemaking and community-building are sprawling due to their connectedness with society and fostering of interpersonal relationships. Increased human interaction can be linked with feelings of belonging that contribute to building a community. By associating the Goldcorp brand with leisure and community, do people connect Goldcorp's operations as being socially responsible?

\subsection{Analysis of urban sponsorship}

These two examples are similar in that they are both monetary purchases, rather than hands-on engagements, and they are both most often interacting with urban individuals. However, the Teck Emergency Centre is providing an essential service whereas Bard on the Beach is creating an environment and community. Teck is providing emergency 
health care to people in need, and Goldcorp is supporting local entertainment. Teck is connecting with their commitment to safety both on-site and at home; Goldcorp is associating their brand with theatre and artistic appreciation.

Both examples have indirect impacts due to the nature of the receiving organization. Part of Teck's donation went directly into the hospital renovation, but part of it also created the "Teck Emergency Centre Innovation Fund, to support research, academic productivity and the development of best practices within the Emergency Department" (St. Paul's Foundation 2012). As a direct result of the St. Paul's Foundation, Teck's strictly monetary contribution was able to build an emergency centre and fund the associated innovative activities.

The same pattern can be seen at Bard on the Beach. Goldcorp's donation primarily went toward the construction of a new stage (aptly named the Goldcorp Stage). The introduction of the new stage attracts more people to the festival therefore growing the Bard community and bringing people together to enjoy local theatre.

However, Bard on the Beach is not limited to hosting performances on stage in Vanier Park. For example, Bard on the Beach partners with local businesses for events like Bike to Bard which support active transportation in the community. There is also the Bard Education program with the mission to "inspire community" through education about William Shakespeare (Bard Education 2016).

This highlights one of the biggest advantages with urban community engagement, rather than rural community engagement, which is the pre-existing framework of development. In Vancouver, Teck wanted to support healthcare and Goldcorp wanted to support local theatre. For Teck, the St. Paul's Foundation was already well-established and respected in the community so Teck could confidently donate that money knowing it would go to good use. For Goldcorp, Bard on the Beach has been performing annually since 1990 with performances and programming growing each year.

This type of hands-off approach would not be possible or effective in a rural environment. It is for this reason, the authors hypothesize that in an urban community, a mining company can indeed "purchase" a social license to operate.

The remainder of this review will focus on basic marketing strategies and how those can be applied to the urban SLO.

\section{Marketing Strategies}

\subsection{Adoption curves}

The diffusion of innovation curve, or the adoption curve, shown in Figure 1 has been relevant since it was introduced in 1962, and this model is still used today (Rogers 2003).

When a new idea or technology is introduced to the market, the rate at which the general population accepts that new idea and integrates into their lives can be plotted on the adoption curve (Figure 1). Starting with the innovators and ranging to the laggards, this curve represents the common trend of uptake for a new idea to permeate a population.
For the case of the mining industry, consider the attitudes of those people in each category. The innovators and the early adopters are likely people who are already engaged with the mining industry, perhaps they themselves or their friends and family are involved in the industry, and do not need strong encouragement to critically consider mining as a potentially sustainable activity. This group of people should be a low priority for mining companies, as they already have a baseline awareness of the industry.

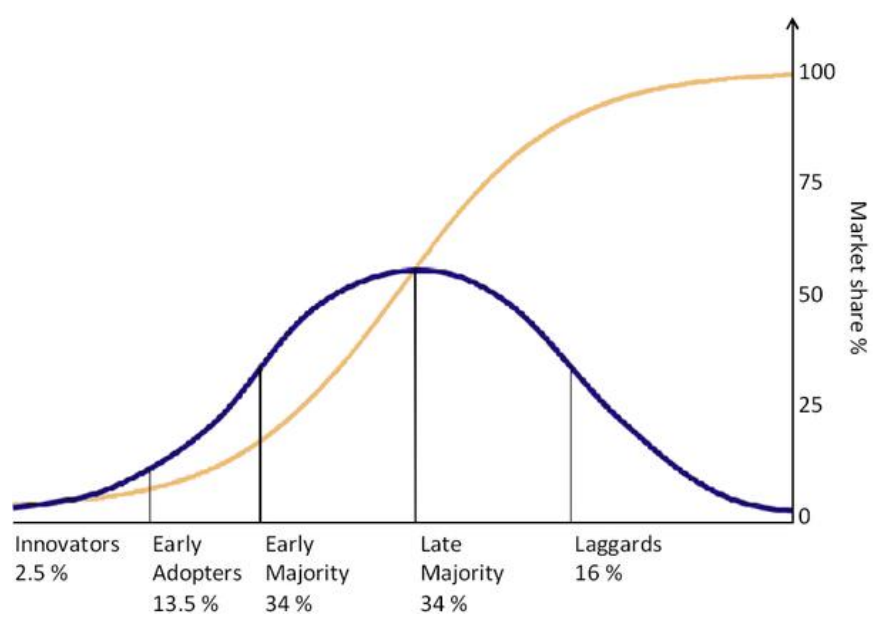

Figure 1. Diffusion of innovation curve. The blue line represents the distribution of successive groups adopting the technology; the yellow line represents how that adoption contributes to market share (Wikimedia 2012, Rogers 2003).

On the other end of the spectrum, the laggards are apathetic towards the industry. They likely have minimal knowledge and do not care to learn more, they may even have negative feelings towards the industry but do not care enough to bother to speak out against it. A small portion of the population may be anti-mining. It will take significant effort and resources to convince this group of stakeholders that thinking about mining is worth their effort.

It can be argued that the middle of the spectrum, the early- and late-majority, is the target market for building urban social capital. These people are probably cognizant of mining as industry, but think about it very infrequently. They understand that mining is necessary to their lifestyles of cars and iPhones and jewelry but they have little concept of the process between finding a rock deep in the ground and turning it into the materials for a television. They are likely not against mining; it is just an activity that does not obviously impact their life so there is no particular reason to think about it.

The diffusion of innovation curve (Figure 1) may accurately describe the transition of the population towards approval or co-ownership of a mining company. In this case, the new technology or idea is earning a social license to operate. The adoption curve model is only accurate if the technology or innovation is a high-quality product that people eventually want to purchase. This qualifier translates to the mining industry, as companies must strive for comparable evidence to back up their claims to social responsibility. 


\subsection{Goal, objective, strategy, tactic}

A commonly used model in marketing is the goal, objective, strategy, tactic or GOST model (Celsi 2014):

- Goal - This is the overall desired outcome of the effort. This should be long term and barely attainable; it will rarely change.

- Objective - Measureable, quantifiable indicators of success. These statements will likely start with a verb.

- Strategy - A conceptual plan, usually task-specific and time-bound, that addresses or executes an objective.

- Tactic - These are the tools that contribute to the strategy.

Any task will have one goal, a couple objectives, a few strategies, and several tactics for each strategy. This is commonly illustrated in a pyramid (Figure 2).

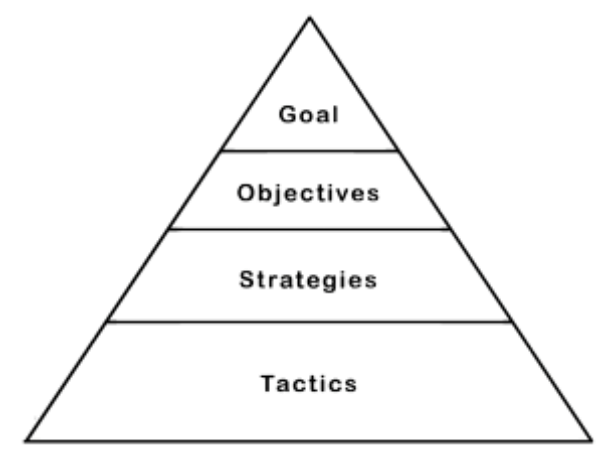

Figure 2. GOST pyramid (Marrinan 2014).

To apply this model to a mining company attempting to earn an urban social license to operate, one stream of the model could be:

- Goal - Earn a social license to operate in the City of Vancouver.

- $\quad$ Objective - Increase approval rating of the mining company by $20 \%$.

- Strategy - Associate the mining industry with positive events and activities in the community.

- Tactic - Support local theatre, sponsor healthcare facilities, get involved in the downtown east side, and promote "green" transportation options like public transit or cycling.

With this model, the objective must be measurable which can present significant challenges when building social capital.

\section{The Social License to Operate}

One of the challenges with the social license to operate is how to measure it. How does a company know if they have earned a social license to operate? Or understand at what phase they are in? This investigation will focus on the Modified "Arrowhead" Model (Thomson and Boutilier 2011).

To quantify the social license, Thomson and Boutilier consider 'stakeholder networks' rather than a 'community' because it extends the reach of influence outside the geographical area (Thomson and Boutilier 2011). It also allows for disagreements between stakeholder networks.

To model how the opinions of different stakeholder networks contribute to the social license, Thomson and Boutilier (2011) used an arrowhead shape and used four factors of determining the proportions of stakeholders who are at each level. This enhanced four-factor model is shown in Figure 3. Each factor in Figure 3 contributes to the SLO as a company or project moves from acceptance through approval to psychological identification.

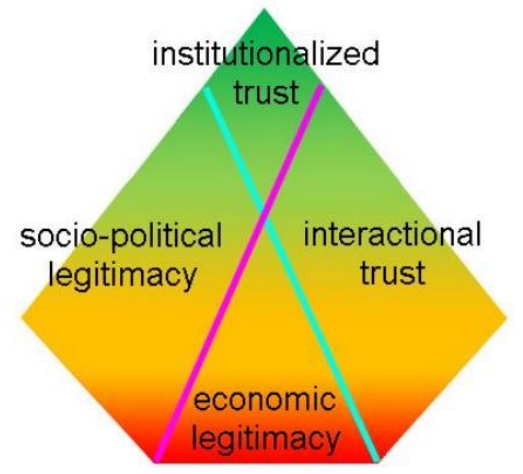

Figure 3. Four factors towards a social license to operate that illustrates the proportion of stakeholders required to achieve different phases of approval/acceptance/co-ownership (Thomson and Boutilier 2011).

\section{The Urban Social License to Operate}

It is proposed that by combining the strategies from the GOST pyramid with factors from the Thomson and Boutilier (2011) arrowhead model, progress towards an urban SLO can be optimized. Each strategy (GOST) contributes toward a factor (Thomson and Boutilier 2011) and has a specific tactic or series of tactics that will contribute to that strategy. An example is shown in Table 1.

Factor 1 is fairly simple and it is likely that most people in the target group (early- to late- majority as described in section 4.1) already recognize the economic legitimacy of the mining industry.

A trend to note in Table 1 for Factor 2a is that all tactics involve engaging with community groups in a limited monetary or value-in-kind way. Contributing to Factor 2a may also have the greatest impact towards social license. In section 0 the concept of relying on pre-existing frameworks was highlighted, and the examples provided in Factor $2 \mathrm{~b}$ in Table 1 do just that. For example, the Vancouver Pride Parade has a pre-established partnership package with several levels (Presenting, Platinum, Gold, Silver) of support that a mining company may choose from.

Working to impact Factor 2a also sets up the company for progress in Factors $2 b$ and 3. This is the premise behind the strategy for $2 \mathrm{a}$, which is to interact with a large number of partners. With each of those partners, a simple contract is proposed in Factor 2b. It is crucial that this is not a contract that requires legal expertise to comprehend, as this can be a barrier for many organizations. It is intended as a scope of work document so both parties understand each other's 
intention when they begin the partnership. Many large events like the Celebration of Light and the Pride Parade have pre- fabricated partnership agreements so it is easy to know what that sponsorship is purchasing.

Table 1. Example of using the GOST method to optimize progress towards a social license to operate using the factors defined by Thomson and Boutilier (2011).

\begin{tabular}{|c|c|c|c|}
\hline \# & Factor & Strategy & Tactic \\
\hline 1. & Economic Legitimacy & $\begin{array}{l}\text { Demonstrate to the community the } \\
\text { importance of mining to their } \\
\text { everyday lives. }\end{array}$ & $\begin{array}{l}\text { Sponsor a recycling drive that raises awareness } \\
\text { for the amount of mineable material in everyday } \\
\text { life (e.g. cans, batteries, appliances). }\end{array}$ \\
\hline \multirow[t]{5}{*}{$2 a$. } & \multirow[t]{5}{*}{$\begin{array}{l}\text { Socio-Political } \\
\text { Legitimacy }\end{array}$} & \multirow{5}{*}{$\begin{array}{l}\text { Contribute to the City's well-being } \\
\text { and demonstrate respect for the local } \\
\text { way-of-life. Interact positively with a } \\
\text { wide range of stakeholders. Limit } \\
\text { engagement to primarily monetary or } \\
\text { value-in-kind. }\end{array}$} & $\begin{array}{l}\text { Donate to an organization that provides support } \\
\text { for homeless people. }\end{array}$ \\
\hline & & & $\begin{array}{l}\text { Donate to a healthcare provider to address } \\
\text { overdose frequency and treatment. }\end{array}$ \\
\hline & & & $\begin{array}{l}\text { Donate to a cycling advocacy group to promote } \\
\text { sustainable transportation. }\end{array}$ \\
\hline & & & $\begin{array}{l}\text { Purchase attractive advertisement space on } \\
\text { public transit. }\end{array}$ \\
\hline & & & $\begin{array}{l}\text { Sponsor community events like Khatsalano } \\
\text { Festival or the Pride Parade. }\end{array}$ \\
\hline
\end{tabular}

\begin{tabular}{|c|c|c|}
\hline \multirow[t]{2}{*}{ Interactional Trust } & \multirow{2}{*}{$\begin{array}{l}\text { Demonstrate the company's } \\
\text { commitment to each organization } \\
\text { with which it partners. If that partner } \\
\text { needs support, work to help. Keep } \\
\text { communication lines open and active. }\end{array}$} & $\begin{array}{l}\text { Sign a simple and concise contract with each } \\
\text { partner. Purpose is to identify expectations and } \\
\text { timeline to both parties; not for future litigation, } \\
\text { no lawyer required. }\end{array}$ \\
\hline & & $\begin{array}{l}\text { If/When interaction is required, respond in a } \\
\text { timely and friendly manner. }\end{array}$ \\
\hline
\end{tabular}

\begin{tabular}{lll}
\hline 3. Institutionalized Trust & $\begin{array}{l}\text { Demonstrate positive relationships } \\
\text { between partners and the company in } \\
\text { the public eye. }\end{array}$ & $\begin{array}{l}\text { Company is hosting a Christmas party? Invite } \\
\text { community partners. Organization is having a } \\
\text { potluck? Company representative is there. }\end{array}$ \\
\hline
\end{tabular}

When the sponsorship is limited to monetary or valuein-kind the effort required to remain responsive to that partner is minimal, which helps to increase the likelihood of success in Factors $2 b$ and 3. It is recommended that each contract have a time limit for how long the contribution is intended to last. This will demonstrate the company's commitment to that partner, it's regard for their interests, and its trust in the community.

\section{Reasons for Anticipated Success}

\subsection{Public spaces}

A common theme to the tactics described in Factor 2a in Table 1 is that those contributions directly impact members of the general public. In particular, events like the Khatsalano Festival and the Pride Parade are all hosted on public space. Admission is free, attendance is enormous, and these events are transformative to the hosting neighbourhood.

This concept is similar to the relationship between Goldcorp and Bard on the Beach. Even though Goldcorp strictly donated money, they have an impact on the general public in a way that promotes community and sharing public space.

Compare this concept to the standard client-consultant relationship. One of the primary reasons companies hire consultants to complete a project is because the consultant has expertise that the company does not. A community organization is like a consultant in that it has more expertise in that community than the company.

The advantage of sponsoring these types of events is that a mining company gets to engage with the public in a very passive way, without any of the efforts typically required in the "traditional" community engagement model. Mining does not need to be at the forefront of most people's lives, rather companies are endeavouring for a background level of institutionalized trust.

Recall the target group of the general public that was discussed in section 4.1. The early- and late-majority of people are not against mining; they just do not know much about it and are not particularly motivated to think about it. People in this group will be extremely hard to attract to mining-specific events because they are so apathetic towards the industry. This is one great advantage to sponsoring existing, successful events and that is people already attend these events providing an opportunity for passive impressions. In 2016, between 250,000 and 500,000 people were drawn to Vancouver's English Bay for each of the three nights of fireworks (CBC news 2016).

This concept would not be successful in a small, rural community because those types of community organizations 
are often not yet established or trusted enough to receive large sums of money. It also challenges smaller communities to develop large-scale plans for their growth.

\subsection{Community health}

Encouraging public space and place making is not just beneficial to the company, it has a positive impact on community health. The chain reaction of building positive public spaces to bring together a community to foster relationships and increase well-being cannot be overstated. Injecting a mining company into the public realm however can be challenging, as most public spaces are not seeking sponsorships or funding for their creation (they tend to be funded publicly). For this reason, the logical work-around is for mining companies to get involved in the activation of that public space. By sponsoring or donating to the opportunities similar to the examples proposed in Table 1 under Factor $2 \mathrm{a}$ then those companies get to be part of the public realm at its most animated state.

\section{Discussion}

One of the main challenges to the efforts of earning a social license for the industry is that even though mining is an activity that facilitates so many of the things we want and need to have in our everyday lives, it is not something an average member of the public ever thinks about. This state of indifference and lack of enthusiasm to care may be the greatest challenge to building social capital in Vancouver.

In a rural community, proximal to a mine site, any individual person likely has some connection to the mine. In contrast, Vancouver does not see/feel/taste/touch/hear about the mining industry directly, or indirectly, on any frequent basis.

For many people, the mining industry also may come with a stigma of pollution or dirtiness or exuberant wealth, so there is a high risk of backlash if engaging in too contrary of a topic. For example, suppose diamond company De Beers sponsored a campaign to end homelessness. Even if De Beers had the best intention to address a critical social issue, the reaction to that campaign might not be positive. This concept is known as congruity and can severely impact the likelihood of success or failure (Jagre et al 2001).

People do not know who the mining players are; they do not recognize company names or projects. Maybe the first step towards co-ownership is getting these words into the public vernacular.

The scope of this impact may not be limited to a particular company, as increased urban awareness may benefit the mining industry as a whole.

\section{Conclusions}

Mining companies may be able to "purchase" a social license to operate in an urban environment by leaning into existing local community networks. In rural environments, a mining company must conduct its own outreach and engage directly to be successful. In urban environments like Vancouver, there is an existing framework of community engagement and public activation that a mining company can simply provide the cash or value-in-kind to support. This network of local organizations can achieve a greater and more meaningful amount of engagement with significantly less effort from the mining company.

\section{References}

ANA (Association of National Advertisers) Survey, 2013. ANA Survey Uncovers Marketers' Continuing Struggle to Validate Sponsorship / Event Marketing Initiatives. https://www.ana.net/content/show/id/28377.

Bard Education, 2016. https://bardonthebeach.org/education.

CBC news, 2016. U.S.A disney team ends honda celebration of light with bang. http://www.cbc.ca/news/canada/british-columbia/u-s-adisney-team-ends-honda-celebration-of-light-withbang-1.3702318.

Celsi, C., 2014. How to differentiate goals, objectives, strategies, and tactics. PR Daily. http://www.prdaily.com/Main/Articles/How_to_differe ntiate_goals_objectives_strategies_a_16995.aspx.

IEG Sponsorship Report, 2015. The deepest sponsorship pockets of 2014. http://www.sponsorship.com/iegsr/2015/08/03/TheDeepest-Sponsorship-Pockets-of-2014--IEG-sTop.aspx.

Jagre, E., J.J. Watson and J.G. Watson, 2001. Sponsorship and congruity theory: A theoretical framework for explaining consumer attitude and recall of event sponsorship. Advances in Consumer Research, 28: 439 445.

Marrinan, J., 2014. What's the difference between a goal, objective, strategy, and tactic? Common Business. http://www.commonbusiness.info /2014/09/whats-thedifference-between-a-goal-objective-strategy-andtactic/.

McClellan, S., 2016. Global sponsorship dollars will reach $\$ 60$ billion in 2016. MediaPost. http://www.mediapost.com/publications/article/266678/ global-sponsorship-dollars-will-reach-60-billion.html.

Rogers, E.M., 2003. Diffusion of innovations ,5th Ed. Free Press, New York.

Rosen, W. and L. Minsky, 2011. Six steps to successful sponsorships. Harvard Business Review. https://hbr.org/2011/07/six-steps-to-getting-sponsorsh.

St. Paul's Foundation, 2012. Teck Emergency Centre. http://helpstpauls.com/2012 /05/30/teck-emergencycentre.

Thomson, I. and R. Boutilier, 2011. Modelling and measuring the social license to operate: Fruits of a dialogue between theory and practice. socialicense.com. http://socialicense.com/publications/Modelling\%20and $\% 20$ Measuring\%20the\%20SLO.pdf.

Wikimedia, 2012. Diffusion of innovation curve. https://commons.wikimedia.org/wiki/File:Diffusion_of _ideas.svg. 